\title{
A review of environmental occurrence, fate, and toxicity of novel brominated flame retardants
}

Ping Xiong ${ }^{1,2}$, Xueting Yan ${ }^{1,2}$, Qingqing Zhu ${ }^{1,2}$, Guangbo Qu ${ }^{1,2,3}$, Jianbo Shi ${ }^{1,2,3}$, Chunyang Liao ${ }^{1,2,3, *}$, and Guibin Jiang ${ }^{1,2}$

${ }^{1}$ State Key Laboratory of Environmental Chemistry and Ecotoxicology, Research Center for Eco-Environmental Sciences, Chinese Academy of Sciences, Beijing 100085, China

${ }^{2}$ College of Resources and Environment, University of Chinese Academy of Sciences, Beijing 100049, China

${ }^{3}$ Institute of Environment and Health, Jianghan University, Wuhan, Hubei 430056, China

*Corresponding author: Dr. Chunyang Liao

Research Center for Eco-Environmental Sciences

Chinese Academy of Sciences

Beijing 100085, China

Tel./Fax: 86-10-6291 6113

E-mail: cyliao@ rcees.ac.cn

Pages: 11

Figures: 6

Tables: 1 


\section{Physicochemical properties and production/usage of NBFRs}

\subsection{Physicochemical properties of NBFRs}

The predicted melting points of the select NBFRs range from $70^{\circ} \mathrm{C}$ to $300^{\circ} \mathrm{C}$, with the exception of TBB and TBPH, whose melting points are not available. The boiling points of these compounds are predicted to be in the range of $371.2^{\circ} \mathrm{C}(\mathrm{TBECH})$ to $676.5^{\circ} \mathrm{C}$ (TBBPA-DBPE). The predicted vapor pressures $\left(1.55 \times 10^{-11}\right.$ to $1.22 \times 10^{-3} \mathrm{~Pa}$ at $25^{\circ} \mathrm{C}$,) indicate that these selected NBFRs have low volatility from water surface, and the values of predicted water solubility $\left(1.6 \times 10^{-7}\right.$ to $7.8 \times 10^{-4} \mathrm{~g} / \mathrm{L}$ at $25^{\circ} \mathrm{C}$, ) suggest that these compounds are almost not dissolved in water. Therefore, it is reasonable to assume that these select NBFRs tend to adsorb in the surface of particles in air and distribute in sediments in rivers and lakes in environment. The $\log K_{o w}$ values of NBFRs are predicted to range from 5.24 (TBECH) to 11.1 (DBDPE), which are well consistent with their extremely low predicted water solubility.

\subsection{Production/usage of NBFRs}

The estimated global production of DBDPE was between 4540 and 22700 tons in 2006 and between 22700 and 45400 in $2012 .{ }^{29}$ In China, the production volume of DBDPE was estimated to be 12000 tons in 2006 with an increasing rate of $85 \%$ per year. ${ }^{30}$ The estimated global production volume of BTBPE was approximately 5000 tons in 1997, which rose to over 16000 tons in $2001 .^{31,32}$ According to the USEPA Inventory Update Reports, the annual production volumes of PBEB and HBB were $10-500$ thousand pounds in 1986 and $4.5-227$ tons in 1998 , respectively. ${ }^{33}$ It is reported that about 600 tons of $\mathrm{HBB}$ and PBT are manufactured in Weifang, China per year. ${ }^{34}$ TBPH has been listed as high production volume chemical by the USEPA. The annual production volume of TBPH in the U.S. was 450-4500 tons from 1990 to 2006, and was 450-4500 tons in 2012. ${ }^{35,36}$ According to the USEPA, TBB was listed as high production volume chemical in $2006 .{ }^{37}$ However, it was removed from the USEPA High Production Volume Information System in 2015, which indicates that its production and import volume in the U.S. is less than 450 tons per year. ${ }^{38}$ The 
estimated production volumes of TBECH in the U.S. were between 4.5 and 226 tons per year from 1986 to $2002 .{ }^{39}$ In the EU, TBBPA-DBPE is classified as low production volume chemical. ${ }^{40}$ In China and the U.S. in 2006, the annual production amount of TBBPA-DBPE was estimated at 4000 and 4500 tons, respectively. ${ }^{41}$ 


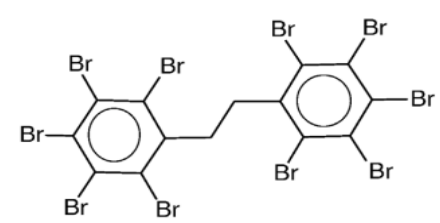

DBDPE<smiles>Brc1cc(Br)c(OCCOc2c(Br)cc(Br)cc2Br)c(Br)c1</smiles>

BTBPE

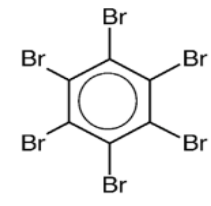

HBB<smiles>CCc1c(Br)c(Br)c(Br)c(Br)c1Br</smiles>

PBEB

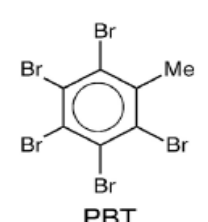

PBT
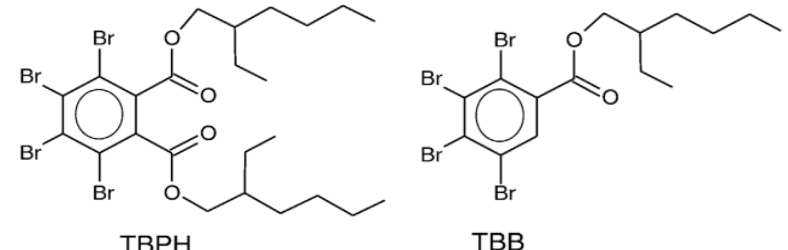<smiles>BrCC(Br)C1CCC(Br)C(Br)C1</smiles>

Figure S1. Chemical structures of select NBFRs. 


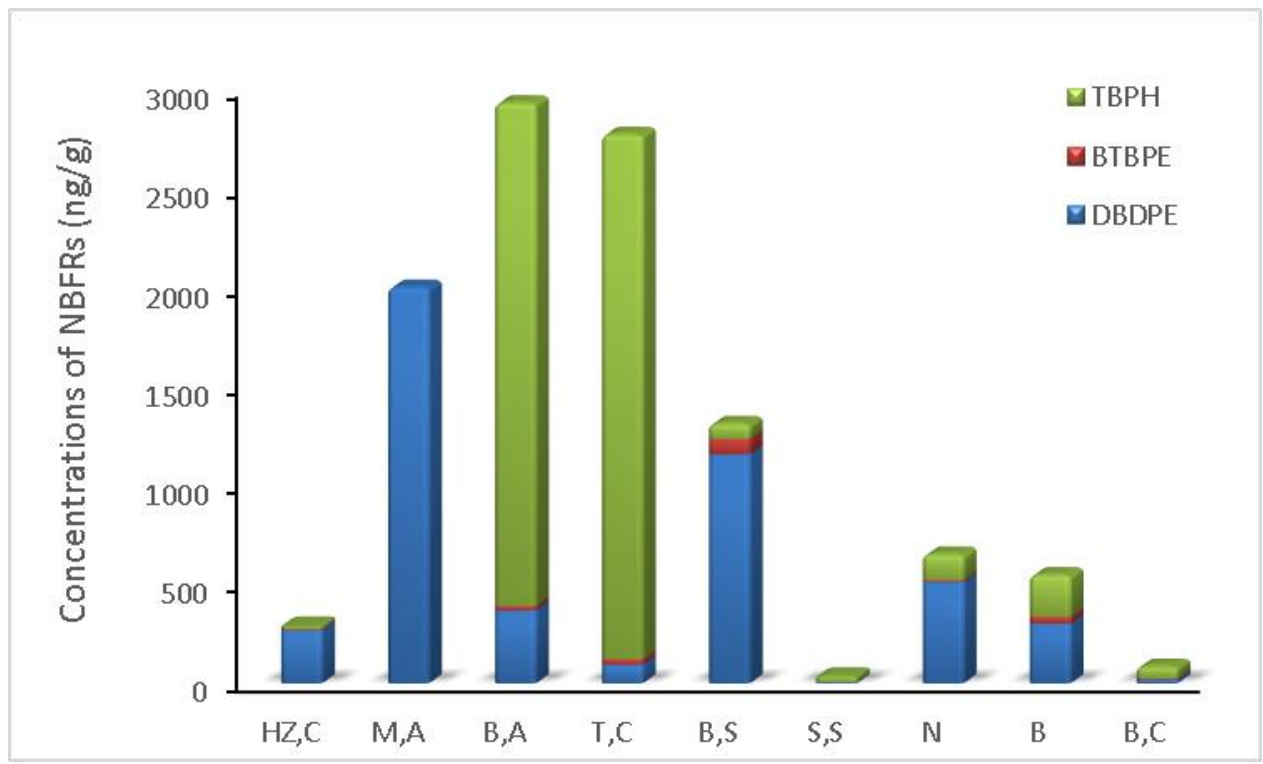

Figure S2. Mean concentrations of DBDPE, BTBPE and TBPH in home dust from different areas. HZ,C: HangZhou, China; M,A: Melbourne, Australia; B,A: Bloomington, USA; T,C: Toronto, Canada; B,S: Barcelona, Spain; S,S: Stockholm, Sweden; N: Norway; B: Belgium; and B,C: Brno, Czech Republic. The data of BTBPE and TBPH are not available from Melbourne, Australia and the data of BTBPE are not available from Stockholm, Sweden. 


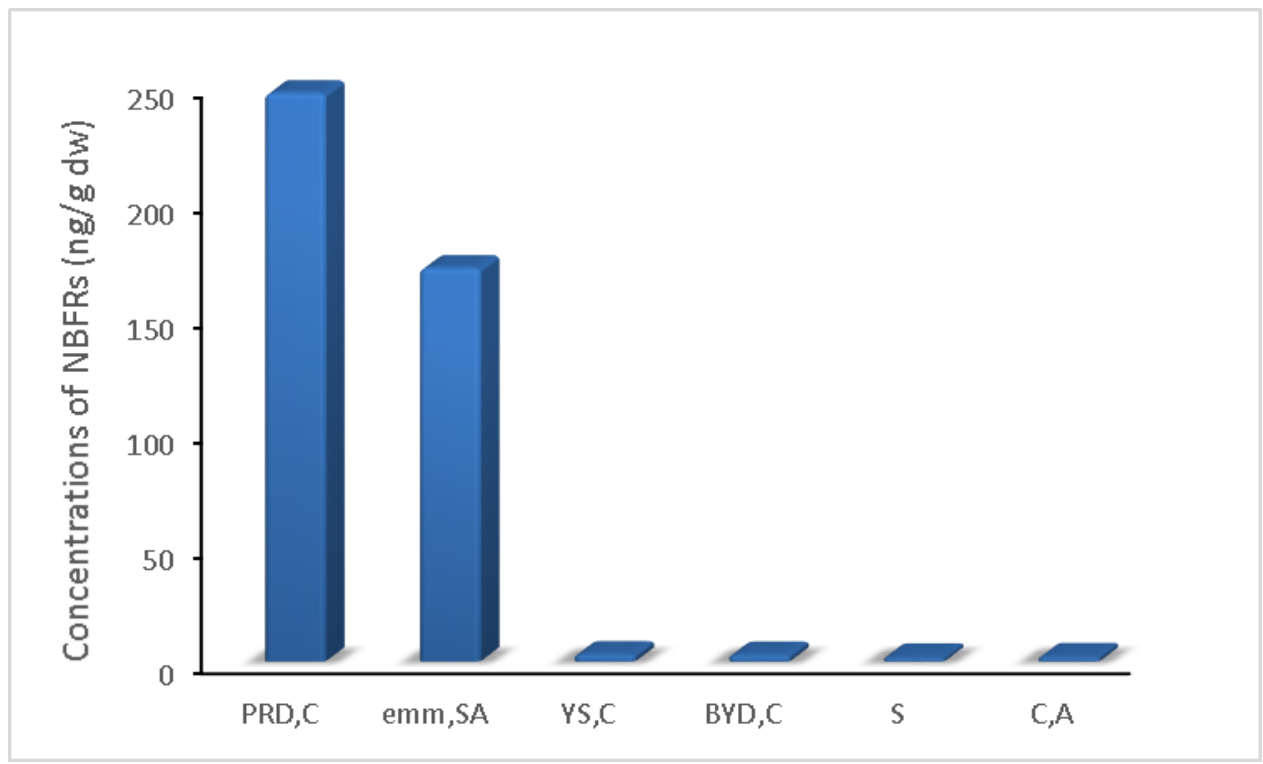

Figure S3. Mean concentrations of DBDPE in sediment from different areas. YS,C: Yellow Sea, China; BYD,C: Baiyangdian, China; S: Sweden; C,A: Chicago, USA; PRD,C: Pearl River Delta, China; and emm,SA: eThekwini metropolitan municipality, South Africa. 


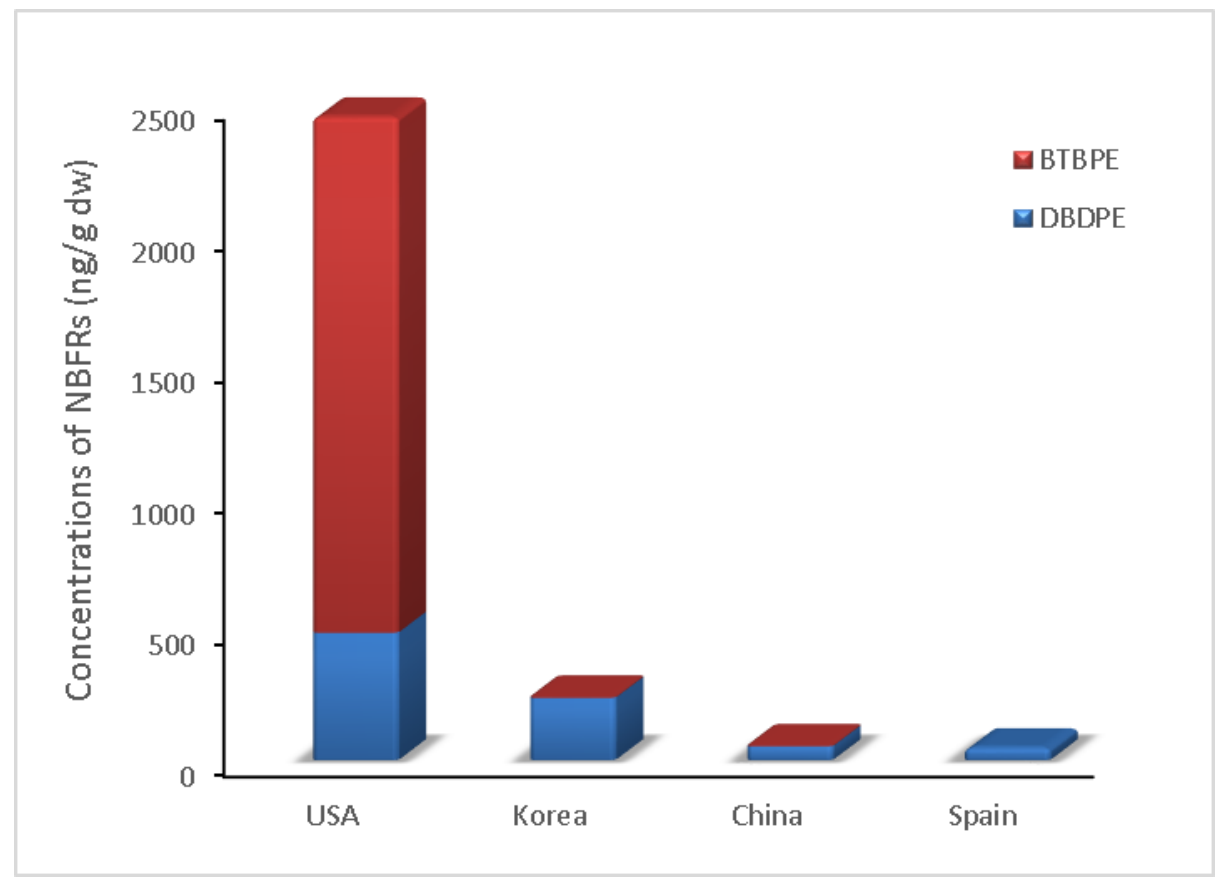

Figure S4. Mean concentrations of DBDPE and BTBPE in sludge from four different countries. The data of BTBPE are not available from Spain. 

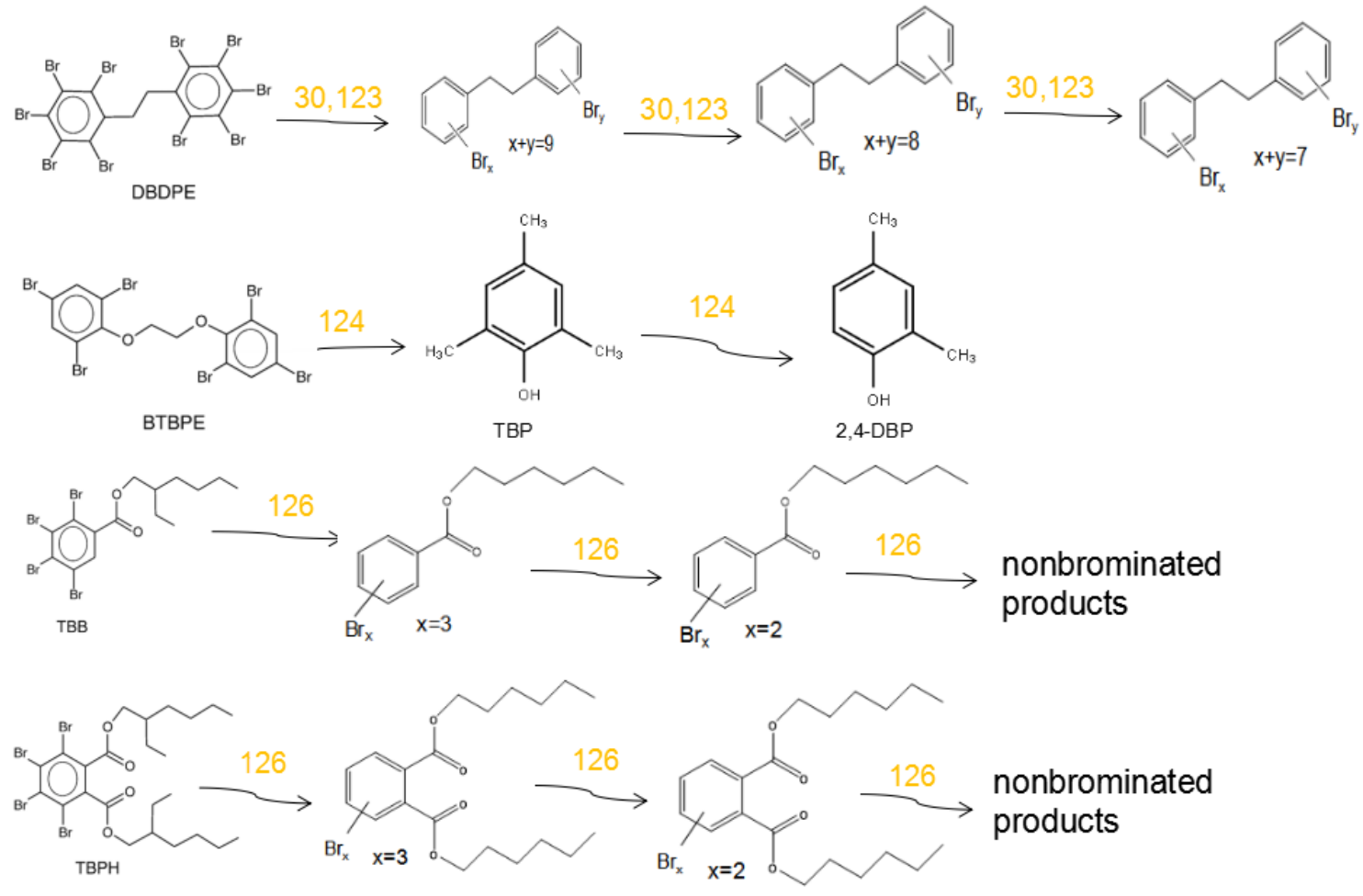

Figure S5. Photodegradation of several NBFRs (refs 30, Wang et al. (2012); 123, Nadjia et al. (2014); 124, Zhang et al. (2016); and 126, Stapleton et al. (2009)). 

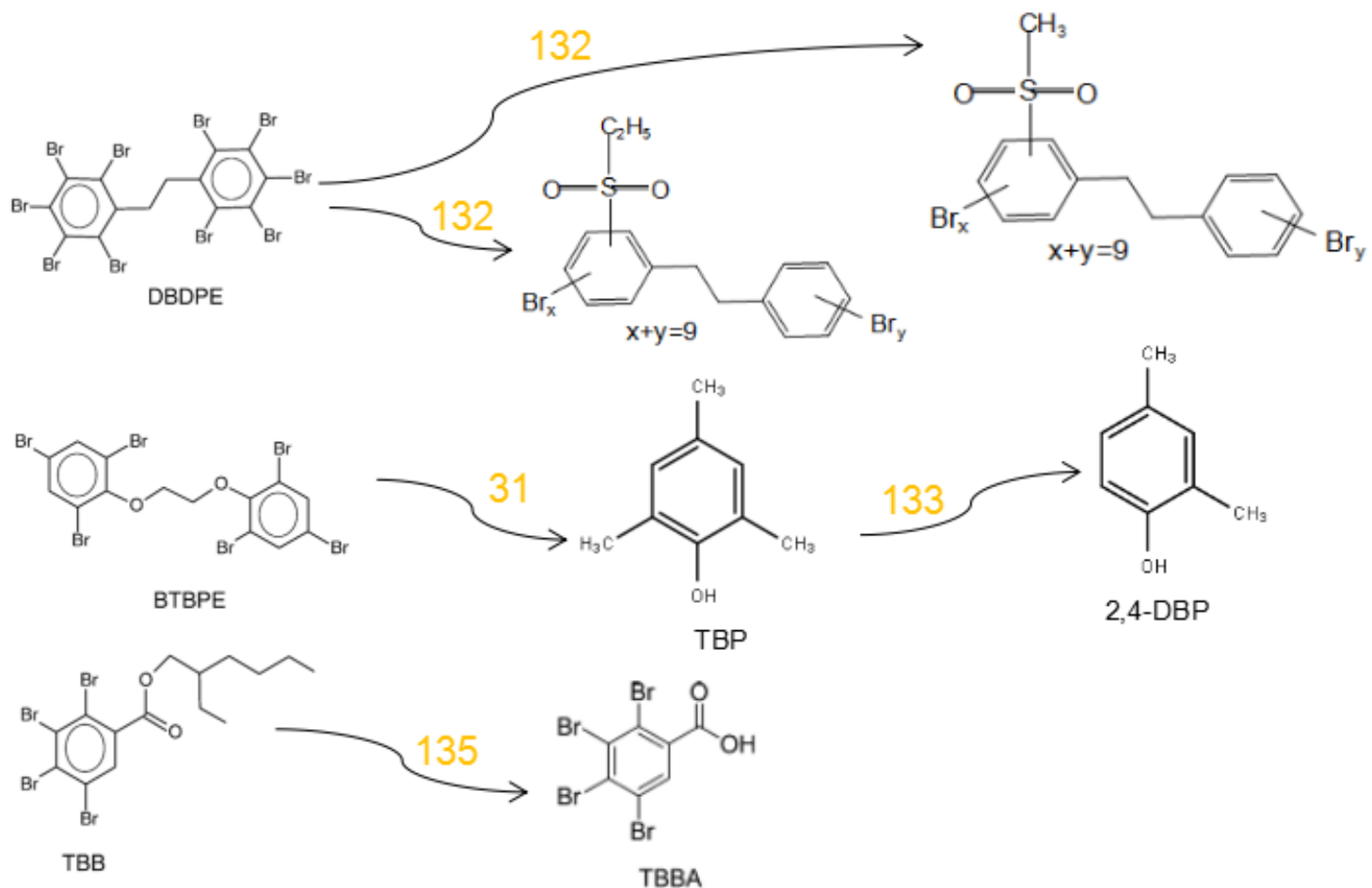

2,4-DBP
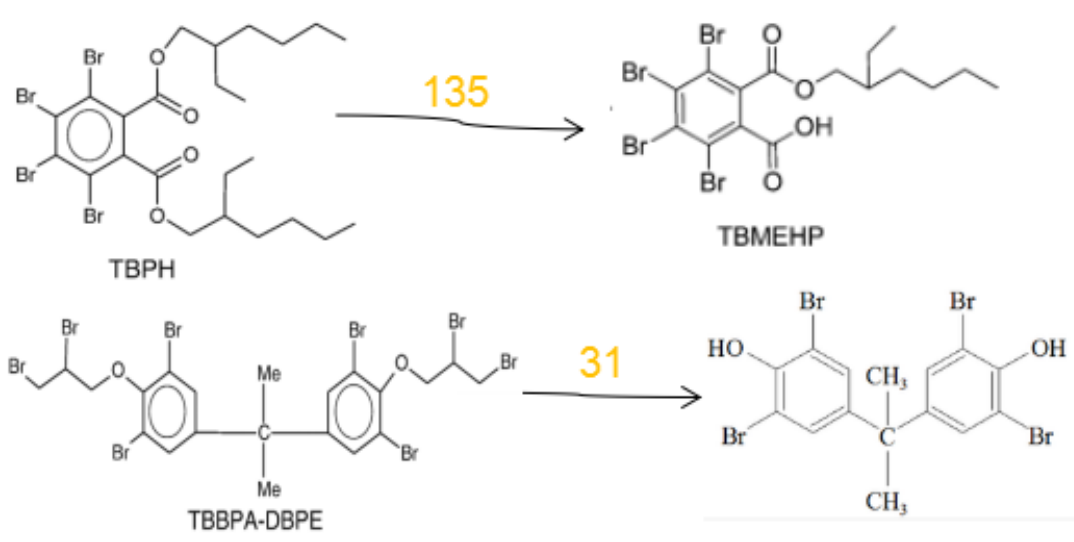

Figure S6. Biodegradation and biotransformation of several NBFRs (refs 31, Jourdan et al. (2013); 132, Wang et al. (2010); 133, Jourdan et al. (2014); and 135, Roberts et al. (2012)) 
Table S1. Selected physicochemical properties of NBFRs

\begin{tabular}{|c|c|c|c|c|c|c|c|c|c|}
\hline Compound & Abbreviation & $\begin{array}{l}\text { Molecular } \\
\text { formula }\end{array}$ & $\begin{array}{l}\text { Molecular } \\
\text { weight }\end{array}$ & $\begin{array}{l}\mathrm{M} \\
\mathrm{pc}\end{array}$ & $\begin{array}{l}\text { elting } \\
\text { int }\left({ }^{\circ} \mathrm{C}\right)\end{array}$ & $\begin{array}{l}\text { Boiling } \\
\text { point }\left({ }^{\circ} \mathrm{C}\right)\end{array}$ & $\begin{array}{l}\text { Vapor pressure } \\
\left(\mathrm{Pa}, 25^{\circ} \mathrm{C}\right)\end{array}$ & $\begin{array}{l}\text { Water solubility } \\
(\mathrm{g} / \mathrm{L})\left(25^{\circ} \mathrm{C}\right)\end{array}$ & $\log K_{\text {ow }}$ \\
\hline Decabromodiphenyl ethane & DBDPE & $\mathrm{C}_{14} \mathrm{H}_{4} \mathrm{Br}_{10}$ & $971.2^{a}$ & $84852-53-9$ & $300^{c}$ & $676.2 \pm 50^{b}$ & $6.0 \mathrm{E}-15^{a}$ & $2.10 \mathrm{E}-07^{a}$ & $11.1^{a}$ \\
\hline 1,2-bis(2,4,6 tribromophenoxy) & BTBPE & $\mathrm{C}_{14} \mathrm{H}_{8} \mathrm{Br}_{6} \mathrm{O}_{2}$ & $687.6^{a}$ & $37853-59-1$ & $222^{d}$ & $556.4 \pm 50^{b}$ & $1.89 \mathrm{E}-10^{d}$ & $2.23 \mathrm{E}-07^{d}$ & $8.9^{d}$ \\
\hline \multicolumn{10}{|l|}{ ethane } \\
\hline Hexabromobenzene & HBB & $\mathrm{C}_{6} \mathrm{Br}_{6}$ & $551.5^{a}$ & $87-82-1$ & $327^{d}$ & $417.5 \pm 40^{b}$ & $1.14 \mathrm{E}-04^{a}$ & $1.6 \mathrm{E}-07^{d}$ & $6.07^{d}$ \\
\hline Pentabromoethylbenzene & PBEB & $\mathrm{C}_{8} \mathrm{H}_{5} \mathrm{Br}_{5}$ & $500.7^{a}$ & $85-22-3$ & $138^{c}$ & $413.3 \pm 40^{b}$ & $3.2 \mathrm{E}-04^{a}$ & $3.5 \mathrm{E}-04^{a}$ & $6.40^{a}$ \\
\hline Pentabromotoluene & PBT & $\mathrm{C}_{7} \mathrm{H}_{3} \mathrm{Br}_{5}$ & $486.6^{a}$ & $87-83-2$ & $287.8^{d}$ & $394.4 \pm 37^{b}$ & $1.22 \mathrm{E}-03^{a}$ & $7.80 \mathrm{E}-04^{a}$ & $6.99^{e}$ \\
\hline 2-Ethylhexyl & TBB & $\mathrm{C}_{15} \mathrm{H}_{18} \mathrm{Br}_{4} \mathrm{O}_{2}$ & $549.9^{a}$ & $183658-27-7$ & N/A & $477.5 \pm 40^{b}$ & N/A & N/A & $7.73^{b}$ \\
\hline \multicolumn{10}{|l|}{ 2,3,4,5-Tetrabromobenzoate } \\
\hline Bis-(2-ethylhexyl) & TBPH & $\mathrm{C}_{24} \mathrm{H}_{34} \mathrm{Br}_{4} \mathrm{O}_{4}$ & $706.1^{a}$ & $26040-51-7$ & N/A & $584.8 \pm 45^{b}$ & $1.55 \mathrm{E}-11^{a}$ & $1.60 \mathrm{E}-06^{a}$ & $10.08^{a}$ \\
\hline \multicolumn{10}{|l|}{ tetrabromophtalate } \\
\hline 1-(1,2-Dibromoethyl)-3,4-dibrom & TBECH & $\mathrm{C}_{8} \mathrm{H}_{12} \mathrm{Br}_{4}$ & $427.8^{a}$ & $3322-93-8$ & $70-76^{d}$ & $371.2 \pm 22^{b}$ & $1.05 \mathrm{E}-04^{e}$ & $6.9 \mathrm{E}-05^{e}$ & $5.24^{e}$ \\
\hline \multicolumn{10}{|l|}{ ocyclohexane } \\
\hline Tetrabromobisphenol A-bis & TBBPA-DBPE & $\mathrm{C}_{21} \mathrm{H}_{20} \mathrm{Br}_{8} \mathrm{O}_{2}$ & $943.6^{a}$ & $21850-44-2$ & $117^{c}$ & $676.5 \pm 55^{b}$ & $1.60 \mathrm{E}-07^{a}$ & $1.60 \mathrm{E}-07^{a}$ & $10.42^{a}$ \\
\hline (2,3-dibromopropyl ether) & & & & & & & & & \\
\hline
\end{tabular}

a): Data from SciFinder originating from calculated properties (ACD/labs Software V9.04).

b): Data from http://www.chemspider.com, which are generated using the ACD/Labs Percepta Platform-PhysChem Modula. 
c): Data from http://www.chemspider.com, originating from experimentally determined properties.

d): Data from https://pubchem.ncbi.nlm.nih.gov/, originating from experimentally determined properties.

e): Data from http://www.chemspider.com, which are generated using the US Environmental Protection Agency's EPISuite ${ }^{\mathrm{TM}}$. 